\title{
Pharmacokinetic Study of Frusemide in Healthy and Cirrhotic Indian Subjects
}

\author{
Dr. Yuvrajsing Dhunnoo MSc, PhD (AIIMS) \\ Lecturer, Department of Health Sciences, University of Mauritius, Mauritius
}

(Received 12 August 2007 and accepted 27 August 2007)

\begin{abstract}
Liver cirrhosis is associated with various complications such as ascites and fluid retention, progressing to development of hepatorenal syndrome, further compromising fluid elimination. Frusemide, a loop diuretic is normally administered to relieve fluid retentions. The kinetics of frusemide has not been conclusively reported in the three types of cirrhosis and among Indian subjects. The aim of the current study was to evaluate the kinetics of frusemide among healthy and Child's A, B and C cirrhosis and compare with earlier data.

24 cirrhotic were selected and classified according to the Child's-Pugh classification. 12 healthy male volunteers were screened and included in the study. $40 \mathrm{mg}$ of frusemide was administered orally to both groups and blood samples were withdrawn at various intervals of time for a duration of $8 \mathrm{hrs}$. The amount of frusemide present in plasma was analyzed using HPLC. The volumes of distribution $\left(\mathrm{V}_{\mathrm{d}}\right)$, area under curve (AUC), systemic clearance $\left(C_{L}\right)$, maximum concentration $\left(C_{\max }\right)$, time for maximum concentration $\left(\mathrm{t}_{\max }\right)$ in healthy volunteers were respectively $4.56 \pm 0.15 \mathrm{~L}, 2258 \pm 530.7,4.97 \pm 1.67 \mathrm{~L} / \mathrm{h}, 892 \pm 49.4$ $\mathrm{ng} / \mathrm{ml}, 85.20 \pm 7.49$ mins. Corresponding values in Group A were 5.00 $\pm 0.31 \mathrm{~L}, 2471 \pm 228.6,6.60 \pm 2.90 \mathrm{~L} / \mathrm{h}, 1021 \pm 47.97 \mathrm{ng} / \mathrm{ml}$ and 88.25 V 2.12 mins; in Group B $7.73 \pm 1.10 \mathrm{~L}, 4038 \pm 154.7,8.84 \pm 0.45 \mathrm{~L} / \mathrm{h}$, $1448 \pm 43.20 \mathrm{ng} / \mathrm{ml}$ and $120 \pm 1.89 \mathrm{mins}$; In group $\mathrm{C}$ cirrhosis $9.69 \pm$ $1.32 \mathrm{~L}, 4085 \pm 131.75,3.49 \pm 1.40 \mathrm{~L} / \mathrm{h}, 1551 \pm 59.02 \mathrm{ng} / \mathrm{ml}$ and 185.7 $\pm 2.68 \mathrm{mins}$ respectively. Significant differences at $1 \%$ and $5 \%$ were observed among the cirrhotic groups and between healthy $\mathrm{v} / \mathrm{s}$ cirrhotic patients.

Data from current study do not correlate with earlier reports, carried mainly in Western population, due to possibly differences in instrumentation, etc but a possible genetic interplay should not be ruled out. Data from cirrhotic patients could not be effectively compared with earlier studies as kinetics of frusemide has not been conclusively been reported in the three categories of cirrhosis.
\end{abstract}

KEY WORDS: Pharmacokinetic, Frusemide, Liver cirrhosis.

INTRODUCTION:

Liver cirrhosis is one among the leading causes of death in the world and continues to represent a significant worldwide healthcare burden ${ }^{1}$, estimated to have caused around 25,000 deaths in the United States in $1997^{2}$. The etiologies of liver cirrhosis are various and among them are drug induced cirrhosis or cirrhosis due to certain infections such as Hepatitis B and C. Pathological conditions such as biliary atresia, cystic fibrosis, gallstones, may also account for cirrhosis in certain conditions. Cirrhosis can be classified in three categories, according to the Child's- Pugh classification, depending on the severity of the disease ${ }^{1}$.

Corresponding Author: Dr. Yuvrajsing Dhunnoo, Email: y.dhunnoo@uom.ac.mu

Copyrighted (C) by Dr. Arun Kumar Agnihotri. All right reserved Downloaded from http://www.geocities.com/agnihotrimed 
Liver cirrhosis is accompanied by a host of complications, specially the hepatorenal syndrome, causing retention of sodium and free water, decrease in renal perfusion and $\mathrm{GFR}^{3}$, thereby leading to edematic, and ascitic conditions.

Frusemide, a loop diuretic acting on the $\mathrm{Na}+/ \mathrm{K}+/ 2 \mathrm{Cl}$ - symport in the luminal membrane of the ascending loop of Henle, inhibits the chloride and sodium reabsorption, but has no effect on the distal nephron ${ }^{4}$. It has been routinely used for the long term treatment of ascites in cirrhotic patients. Frusemide is an organic acid which is $96-98 \%$ plasma bound thereby limiting its delivery to the site of action. Pre-systemic metabolism of frusemide is carried out by the intestine while systemic clearance of frusemide is mainly performed by the kidneys with contributions from the intestine and the liver. Since $30-50 \%$ of filtered sodium is reabsorbed in the loop of Henle using this transport system, frusemide has high natriuretic properties. At high dosage it may also increase sodium excretion up to $30 \%$.

Presence of edema, due to renal malfunctioning, in cirrhosis, increases volume of distribution, altering drug bioavailability. In severe proteinuria, higher dosage of frusemide is required to achieve adequate free drug concentrations given that urinary albumin binds frusemide and reduces its effectiveness. Clinical non-responders tend to have a decreased fraction of loop diuretics excreted in urine, thereby predisposing them to the side effects of frusemide. Frusemide though not being significantly metabolized by liver may lead to severe side effects such as hyperuricaemia, electrolyte disturbances such as hypokalaemia and the hepatorenal syndrome observed in cirrhotic patients ${ }^{6}$. Furthermore, genetic traits, inter population variations and environmental factors may also significantly contribute to variability in drug response and disposition, thereby leading to a major clinical problem ${ }^{7,8}$. Kinetics of frusemide have been earlier reported in both compensated and decompensated cases of liver cirrhosis, but reported studies were mainly carried out in Western population, using either intravenous frusemide or at a dose of 80 $120 \mathrm{mg}$ orally. However, no studies have been reported on the kinetics of $40 \mathrm{mg}$ oral frusemide among Indian subjects.

The current study has been carried out among healthy and cirrhotic Indian subjects, with the aim to assess the pharmacokinetic parameters of
$40 \mathrm{mg}$ oral frusemide and to compare the generated kinetic data with earlier reported studies.

\section{METHODOLOGY:}

Patient recruitment: The study population included 24 cirrhotic patients. The cause and diagnosis of cirrhosis was identified based on clinical, biochemical and histological findings. Physical examination, nutritional status assessment including serum albumin, BMI, and Child's Pugh's Classification were determined. Recruited patients did not have any other diagnosed disease and no history of fresh internal bleeding. Prior to start of the study, patients were asked to stop frusemide intake 48 hrs prior to start of the test.

Volunteer Recruitment: 12 male volunteers in the age group of 24-29 years were recruited. Health status was ascertained by carrying out various biochemical tests, immunological tests and hematological examinations.

Collection of Study sample: Prior to start of the study, all subjects were fasted overnight but water intake was allowed. The cirrhotic and the healthy volunteers, all had $40 \mathrm{mg}$ of oral frusemide and blood samples were collected in heparinised tubes at specified time intervals following drug administration, up to six hours. Blood samples were centrifuged at $4000 \mathrm{rpm}$ for 5 mins, the supernatant withdrawn and stored in Eppendorf tubes at $-20^{\circ} \mathrm{C}$ till the analysis.

Reagents: Frusemide (99.9\%) purity was kindly donated by Aventis Pharma Ltd, India. Acetonitrile (HPLC grade) and Methanol (HPLC grade) were purchased from s.d fine chemical ltd India. Milli Q water was obtained from Millipore water systems, at a filter size of $0.22 \mathrm{~mm}$. All solutions were degassed under vacuum before use. Glacial acetic acid (HPLC grade), $\mathrm{HCl}$ and $\mathrm{NaOH}$ pellets, were all brand products of Merck Ltd. The mobile phase consisted of a mixture of ACN-0.01 $M$ sodium acetate, which was prepared by mixing ACN and degassed milli-q water in a ratio of $25: 75$. PH was adjusted to 5.0 with $4.0 \mathrm{M} \mathrm{NaOH}$. The final mixture was degassed under vacuum before use.

Instrument Used: The HPLC instrument consisted of a 515 Waters (USA) pump and UV detector. The column was a $30 \mathrm{~cm}^{\prime} 3.9 \mathrm{~mm} \mathrm{~m}$ Bondapack C18 reversed phase column, particle size $10 \mathrm{mM}$ (Waters Assoc). The whole system was controlled by a Millenium Version 2000 Unix computer programming system. The flow rate was adjusted at $2.0 \mathrm{ml} / \mathrm{min}$ at an ambient 
temperature. The detection was followed by using a simple UV lamp detector calibrated at $280 \mathrm{~nm}$. The pressure varied between 1812-2012 psi. Retention times were 5.0 mins and total run time was 10 mins.

Pharmacokinetic Parameters: Concentration time curves of frusemide in plasma were drawn, where values of Cmax and tmax were extrapolated. The area under curve (AUC) was determined by trapezoidal rule.

Value of $\beta$ (elimination constant) was calculated from the elimination phase of the concentration time curve, using the following equation:

$$
\beta=-2.3 \log (\mathrm{Y} 2-\mathrm{Y} 1) /(\mathrm{X} 1-\mathrm{X} 2)
$$

(Where, Y2 and Y1 are the concentration values corresponding to the $Y$ axis, and $X 1$ and $X 2$ are the time intervals corresponding to the $X$ axis.)

Volume of distribution $\left(\mathrm{V}_{\mathrm{d}}\right)$ was calculated using the following formula:

$$
\mathbf{V}_{\mathbf{d}}=\operatorname{Dose} /(\mathbf{A U C} \cdot \boldsymbol{\beta})
$$

Systemic clearance $\left(\mathrm{Cl}_{\mathrm{s}}\right)$ was determined by:

$$
\mathrm{Cl}_{\mathrm{s}}=\mathrm{Dose} / \mathrm{AUC}
$$

\section{RESULTS:}

Area Under Curve (AUC): In healthy volunteers, the AUC, representing the concentration of frusemide present in plasma, was $2258 \pm 530.7 \mathrm{ng} / \mathrm{ml} \mathrm{hr}$. In groups $\mathrm{A}, \mathrm{B}$ and $\mathrm{C}$ cirrhosis, corresponding values were $2471 \pm$ 228.65, $4038 \pm 154.7$ and $4085 \pm 131.75 \mathrm{ng} / \mathrm{ml}$ $\mathrm{hr}$ respectively. (Figure 1)

The difference in AUC between volunteers and group A patients was not statistically significant. However, AUC difference between healthy volunteers and groups $\mathrm{B}$ and $\mathrm{C}$ patients was statistically significant at $1 \% \quad(\mathrm{p}<0.01)$. Significant differences were also observed in AUC for groups $B$ and $C$ vis a vis group $A$ $(p<0.01)$. No statistical difference in AUC was observed between groups $\mathrm{B}$ and $\mathrm{C}$ of patients.

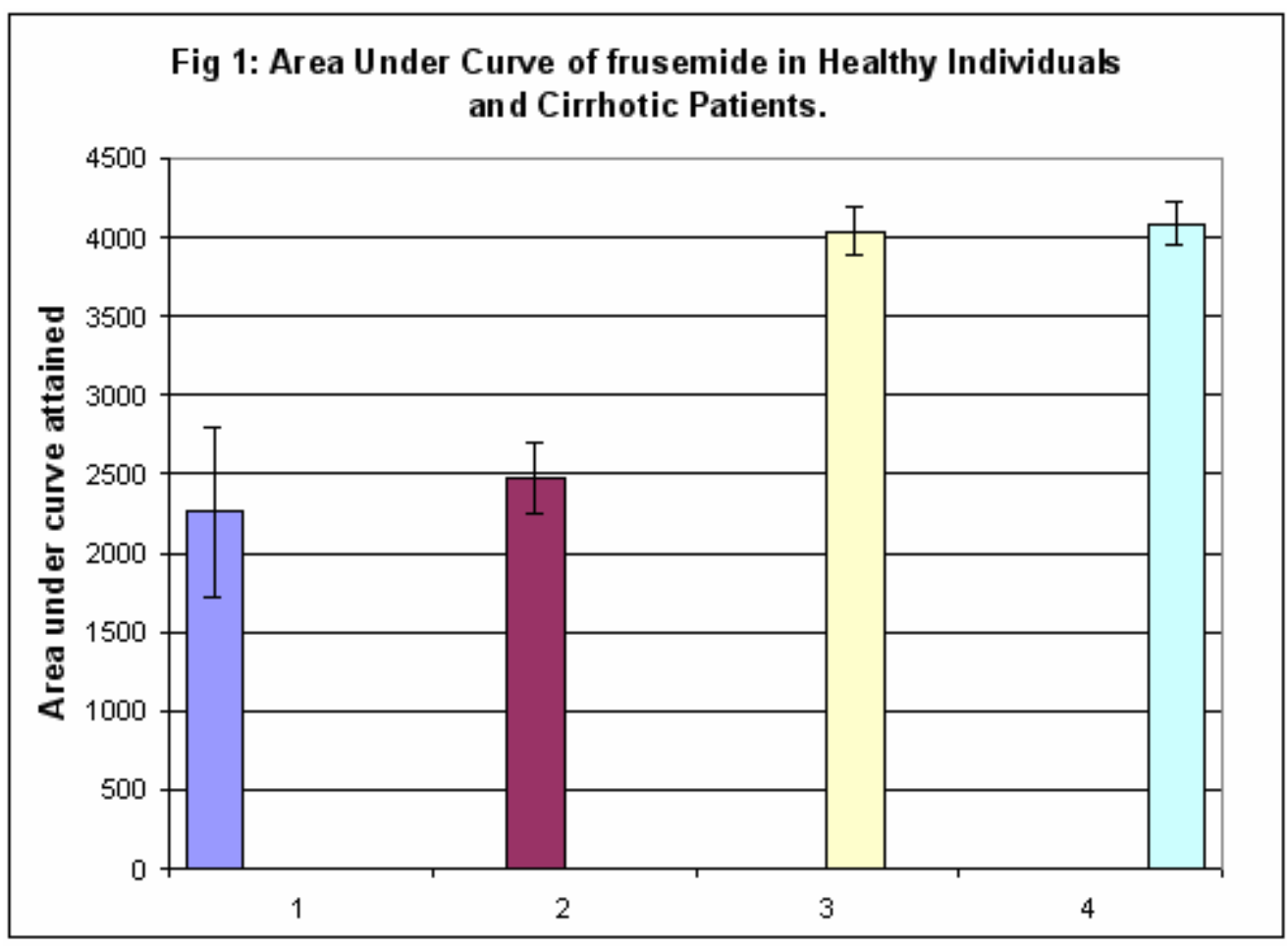

Figure 1: Figure representing the areas under the curves attained in Healthy individuals and cirrhotic patients. Area under the curve is representative of the concentration of the drug in plasma, calculated using the trapezoidal rule. 1: Healthy Volunteers; 2: Group A Patients; 3: Group B Patients; 4: Group C Patients. 
Volume of distribution $\left(V_{d}\right)$ : Mean volume of distribution $\left(\mathrm{V}_{\mathrm{d}}\right)$ in volunteers and group $\mathrm{A}, \mathrm{B}$ and $\mathrm{C}$ cirrhosis were respectively $4.56 \pm 0.15 \mathrm{~L}$, $5.00 \pm 0.31 \mathrm{~L}, 7.73 \pm 1.10 \mathrm{~L}$ and $9.69 \pm 1.32 \mathrm{~L}$. There was no statistical difference between healthy volunteers and group A patients. However, statistical significance was observed between volunteers and $\mathrm{B}$ and $\mathrm{C}$ group of cirrhosis $(p<0.01)$. Significant differences were also observed between $\mathrm{A}$ and $\mathrm{C}$ group of cirrhotics at $5 \% \quad(p<0.05)$. No significant differences were observed between groups B and C. (Figure 2)

Systemic clearance $\left(\mathrm{CL}_{\mathbf{s}}\right)$ : In healthy subjects systemic clearance $\left(\mathrm{CL}_{\mathrm{s}}\right)$ was calculated to be $4.97 \pm 1.67 \mathrm{l} / \mathrm{h}$, and $6.60 \pm 2.90,8.84 \pm 0.45$, and $3.49 \pm 1.40 \mathrm{l} / \mathrm{h}$ respectively in Child's A, B and $\mathrm{C}$ cirrhosis. Clearance increased significantly among cirrhotics in comparison to volunteers $(\mathrm{p}<0.05)$. However in $\mathrm{C}$ group of cirrhosis, systemic clearance decreased considerably. (Figure3).
Mean Maximum Plasma Concentrations of Frusemide $\left(\mathbf{C}_{\text {max }}\right)$ : Maximum plasma frusemide concentration attainable in healthy volunteers was calculated at $892 \pm 49.4 \mathrm{ng} / \mathrm{ml}$, whereas in the various categories of Childs classification, they were respectively $1021 \pm 47.97,1448 \pm$ 43.20, $1551 \pm 59.02 \mathrm{ng} / \mathrm{ml}$. Whereas no significant difference was observed between healthy subjects and A group of cirrhosis, B and $\mathrm{C}$ groups of cirrhosis demonstrated significant difference in $\mathrm{C}_{\max }$ values vis a vis volunteers $(\mathrm{p}<0.01)$. (Figure 4)

Time taken to attain Maximum Plasma Concentration $\left(t_{\max }\right): t_{\max }$ values in healthy volunteers and in groups $\mathrm{A}, \mathrm{B}$ and $\mathrm{C}$ of cirrhosis were as follows: $85.20 \pm 7.49,88.25 \pm 2.12,120$ \pm 1.89 and $185.7 \pm 2.68$ minutes respectively. Group A and volunteers displayed no significant difference in $\mathrm{t}_{\max }$ values, however, significant differences at $1 \%$ were observed between $B$ and $\mathrm{C}$ group of cirrhosis. (Figure 5)

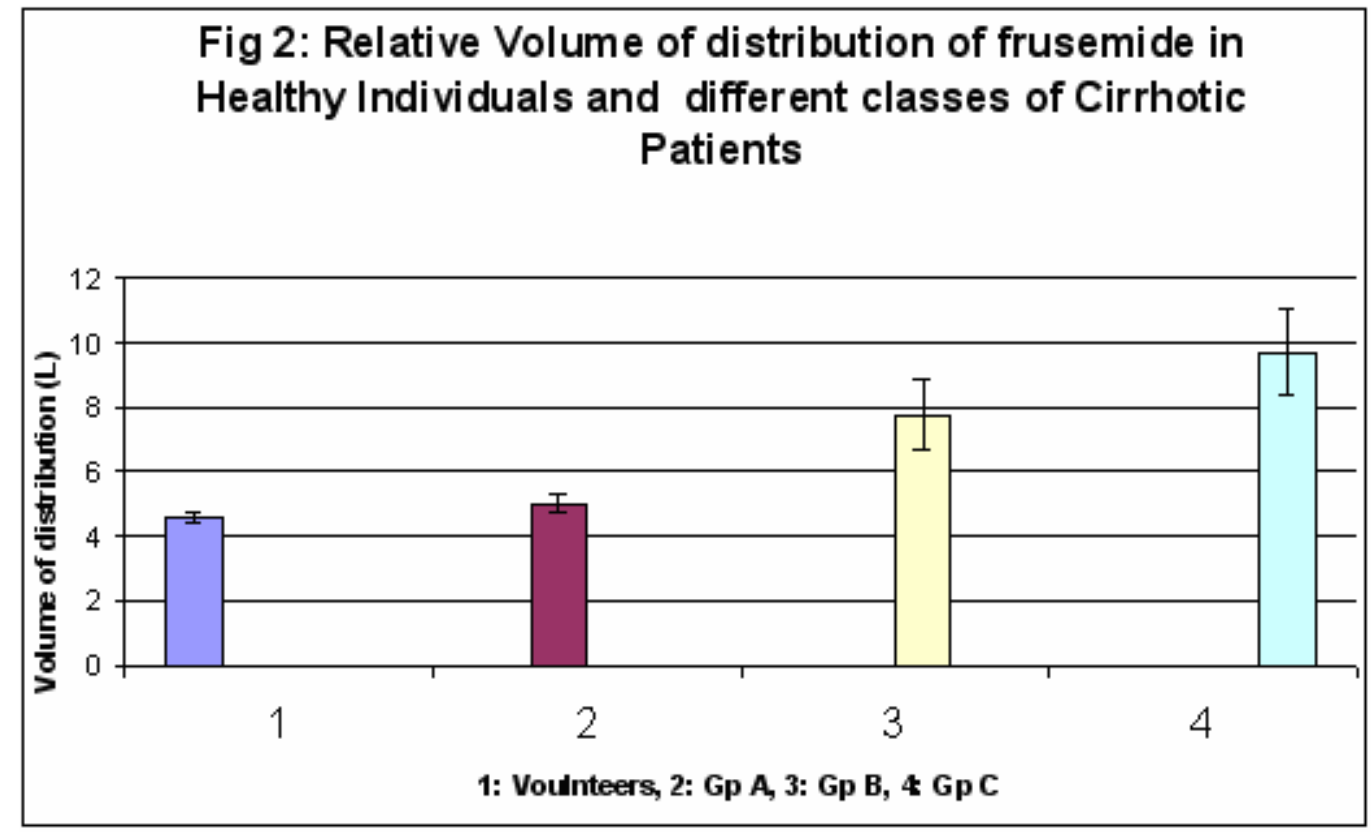

Figure 2: Relative volume of distribution of frusemide in volunteers and different categories of cirrhosis. Volume of distribution calculated gives an indication of rate of cirrhosis. 1: Healthy Volunteers; 2: Group A cirrhosis; 3 Group B cirrhosis; 4: Group C cirrhosis. 


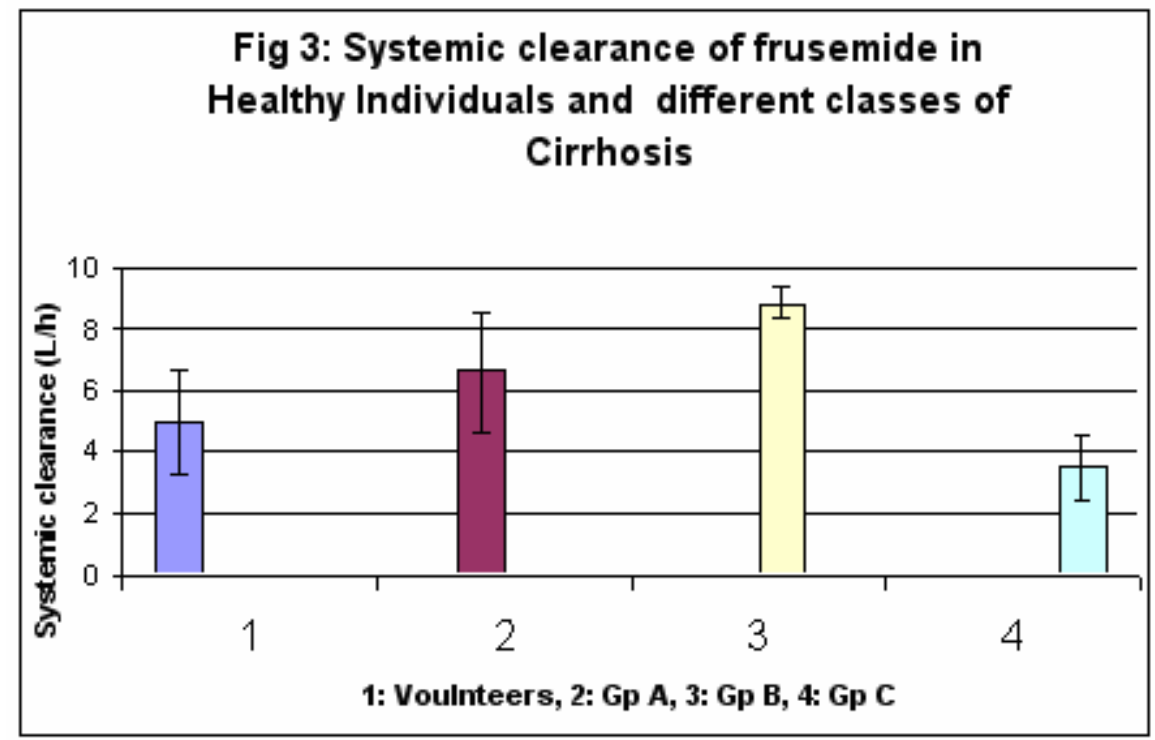

Figure 3: Systemic clearance was calculated using the formula, Clearance indicative of the liver functions. Significant differences was observed between healthy individuals and Group B and $C$ cirrhotic patients

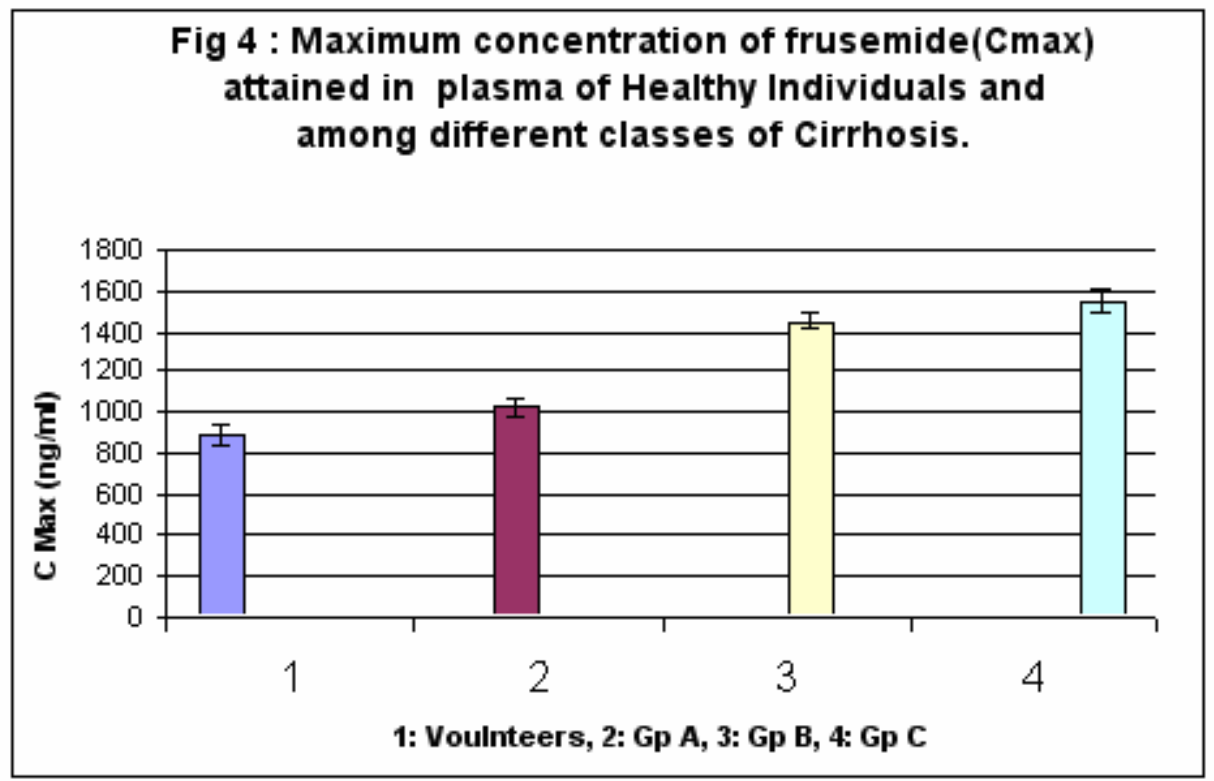

Figure 4: Maximum plasma concentration of frusemide was calculated using the formula mentioned. Significant difference at $5 \%$ was observed between healthy individuals and cirrhotic patients. An inter-group difference among cirrhotic patients was also observed. 


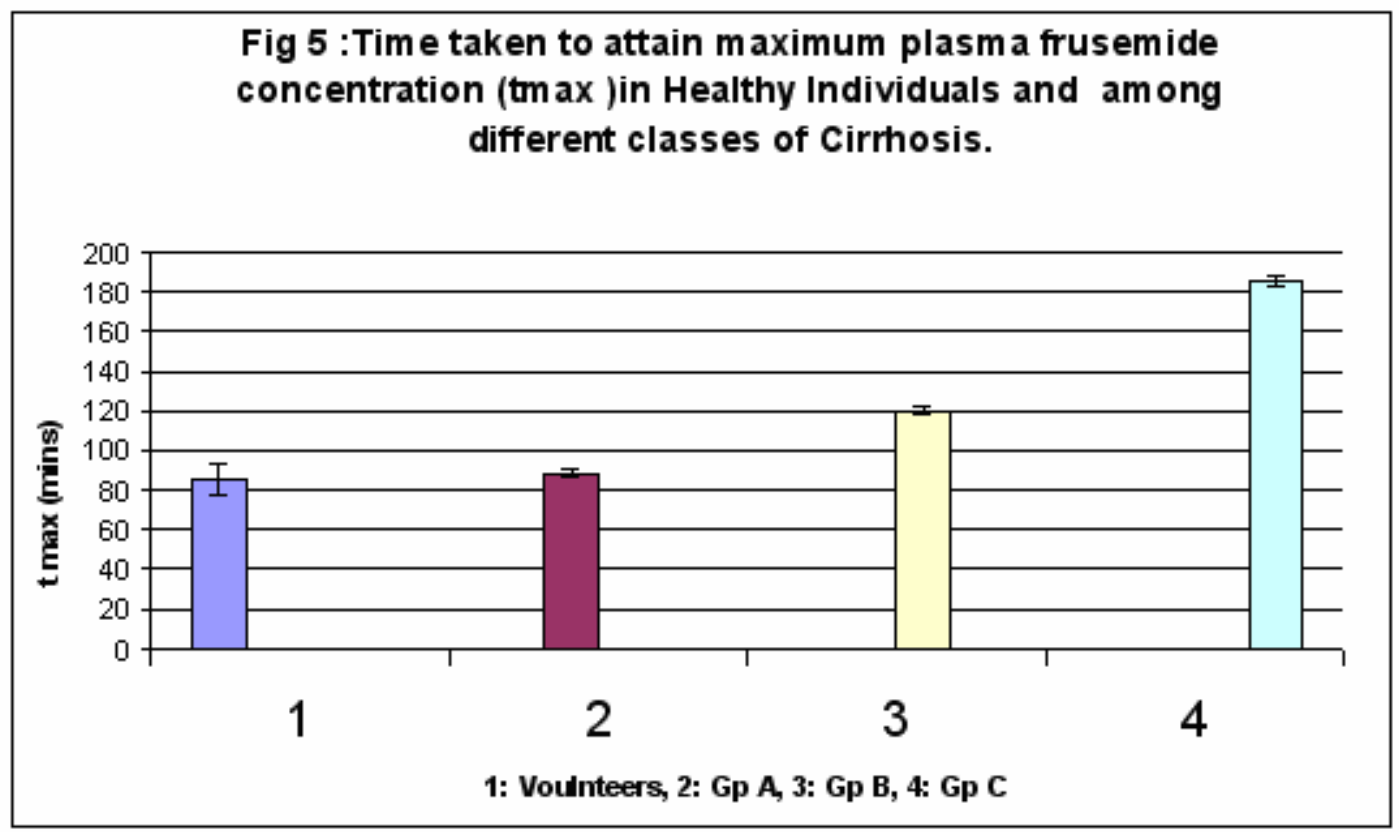

Figure 5: $t_{\max }$ values have been calculated using the formula. $t_{\max }$ values were significantly different between the healthy individuals and the different classes of cirrhotic patients.

\section{DISCUSSION:}

Liver cirrhosis highly influences the dynamic state of the human body. Earlier reports have suggested altered kinetics of a spectrum of drugs such as fluconazole ${ }^{9}$, omeprazole ${ }^{10}$ and a host of other drugs, which are generally administered during cirrhosis. Several kinetic studies in cirrhosis have been conducted, but there has been no conclusive study on the three types of cirrhosis and also kinetic studies among Indian population. The objectives of this study was to shed light on the kinetics of frusemide among healthy and three types of cirrhosis among Indian population and evaluate any possible deviations from the reported studies.

The kinetics of frusemide among Indian volunteers was not in accordance to previously reported data generated from healthy individuals. Earlier reported $\mathrm{t}_{\max }$ values ranged between 60 $70 \mathrm{mins}^{11}$ and $100-150 \mathrm{mins}$ after $40 \mathrm{mg}$ and 80 $\mathrm{mg}$ of oral frusemide respectively in healthy volunteers. In the current study, the $t_{\max }$ value among Indian volunteers was observed to be 90 mins. The volunteers had fasted overnight, but some had breakfast after drug administration. Since food tends to retard kinetics of frusemide $^{\mathbf{1 2}}$, this might have possibly led to observed increase in $t_{\max }$ value. However, the increase in $t_{\max }$ could also be due to slow absorption kinetics amongst Indian Subjects.
Current calculated $\mathrm{C}_{\max }$ value $(0.904 \pm 0.452$ $\mathrm{ng} / \mathrm{ml}$ ) in healthy volunteers was lower than earlier reported values ${ }^{11}$, which could be explained to the difference in administered dose of frusemide (40 mg v $/ \mathrm{s} 80 \mathrm{mg}$ ). Bioequivalence could also be affected by the nature of formulations used ${ }^{13}$. Correspondingly, mean area under curve $(2.23 \pm 0.5 \mu \mathrm{g} / \mathrm{ml} \mathrm{h})$ were lower among Indian volunteers in view of the lower $\mathrm{C}_{\max }$ and $\mathrm{t}_{\max }$ values. The mean half-life values reported are divided on this issue. Higher mean half- life values have been reported elsewhere, but studies conducted by Rupp et $\mathbf{a l}^{14}$ and Cutler et al $^{15}$ have reported similar values as observed in our study. Age ${ }^{16}$, study design ${ }^{17}$, analytical methods and drug formulation ${ }^{18}$ may also alter the course of the drugs in the body, thereby explaining the difference in the observed difference in trend.

Among the cirrhotic groups, observed kinetic parameters were not in accordance to earlier reported values. The $\mathrm{C}_{\max }$ and $\mathrm{t}_{\max }$ in our study increased proportionally in categories A, B and $\mathrm{C}$ of cirrhosis vis a vis healthy volunteers. The increase in $t_{\max }$ is due to presence of edema of the gut along with changed motility, which is predominant in cirrhosis ${ }^{19}$. It is also reported that cirrhosis causes prolongation of gastric emptying time (GET), leading to delayed absorption and thereby raising $\mathrm{C}_{\max }$ and $\mathrm{t}_{\max }{ }^{20,21}$. However,

Copyrighted (C) by Dr. Arun Kumar Agnihotri. All right reserved 
current $\mathrm{C}_{\max }$ and $\mathrm{t}_{\max }$ could not be compared to earlier reports, due to non availability of data on these parameters.

Current observed mean AUC increased in parallel with severity of disease. The increase in AUC among the three type of cirrhosis could be explained due to decreased serum albumin level, hence affecting its binding to frusemide. The increase in AUC level could also be due to decreased systemic clearance, responsible for the observed increase in volume of distribution and half-life. The drug clearance in Group $\mathrm{C}$ is also further significantly reduced owing to a decrease in systemic clearance. The volume of distribution reported earlier ${ }^{22,23,24}$ correlated to some extent to that observed in our group $\mathrm{C}$ patients. This indicates that earlier studies might have been specifically conducted among Child's C cirrhotics. The mean albumin levels among cirrhotics (3.55 \pm 0.34 group A, $3.08 \pm 0.22$ group $\mathrm{A}$, and $2.54 \pm 0.22$ group $\mathrm{C} \mathrm{mg} \%$ respectively) in the current study were lower in comparison to volunteers $(4.75 \pm 0.25)$. It has been earlier reported that a decrease in protein binding $^{25}$ causes an increase in $\mathrm{V}_{\mathrm{d}}$, thereby justifying the increase in the volume of distribution among cirrhotics. Similar trend in volume of distribution has been reported with lidocaine $^{\mathbf{2 6}}$, diazepam ${ }^{27}$ and ampicillin ${ }^{28}$ among cirrhotic patients. Current $\mathrm{V}_{\mathrm{d}}$ increase in our group $\mathrm{C}$ patients, could also be due to the possible development of ascites during the course of the study. Our data of $\mathrm{V}_{\mathrm{d}}$ correlate with earlier reports, suggesting that earlier studies might have explored kinetics of frusemide in group C patients. Most data sources available, do not distinguish between the types of diabetes, thereby rendering comparison with earlier studies difficult.

Reports on the systemic clearance $\left(\mathrm{C}_{\mathrm{L}}\right)$ illustrative of the drug clearance from the body were variable (Table 1). Whereas some studies have reported decreased frusemide clearance among cirrhotic patients ${ }^{\mathbf{2 2 , 2 3 , 2 9}}$, others have reported high clearance rate in compensated cirrhosis, and no difference in decompensated groups $^{24}$. Earlier reports did not mention about the stages of cirrhosis, thereby making it difficult to compare currently calculated values. As volume of distribution is inversely proportional to $\mathrm{C}_{\mathrm{L}}$, our observations are justified by the observed increase in volume of distribution with a paralleled decrease in systemic clearance among the three types of cirrhosis.

Table 1: Summary of reported kinetics of frusemide in cirrhotic patients

\begin{tabular}{|c|c|c|c|c|c|}
\hline $\begin{array}{c}\text { Pharmacokinetic } \\
\text { parameters }\end{array}$ & $\begin{array}{c}\text { Dose (mg) } \\
\text { /Administered } \\
\text { Route }\end{array}$ & $\begin{array}{c}\mathbf{t}_{\max }(\min ) / \\
C_{\max }(\mu \mathrm{g} / \mathrm{ml})\end{array}$ & $\mathbf{t}_{1 / 2}(\operatorname{mins})$ & $\mathbf{V}_{\mathrm{d}}(\mathbf{L})$ & $\mathrm{C}_{\mathrm{L}}(\mathrm{L} / \mathrm{h})$ \\
\hline 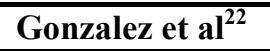 & $40 /$ iv & NA & $81.0 \pm 8.0$ & $10.7 \pm 2.2$ & $6.6 \pm 1.74$ \\
\hline${\text { Verbeeck et } \mathrm{al}^{23}}^{23}$ & $80 /$ iv & NA & $79.4 \pm 18.3$ & $12.1 \pm 1.3$ & $8.52 \pm 0.96$ \\
\hline \multirow{2}{*}{ Traeger et al $^{24}$} & \multirow{2}{*}{$40 /$ iv } & \multirow{2}{*}{ NA } & $65.4 \pm 14.4 \mathrm{C} *$ & $6.92 \pm 0.75 \mathrm{C} *$ & $4.83 \pm 1.32 \mathrm{C} *$ \\
\hline & & & $110 \pm 32.4 \mathrm{D} *$ & $11.42 \pm 3.84 \mathrm{D} *$ & $2.64 \pm 1.02 \mathrm{D} *$ \\
\hline Sawhney et al $^{29}$ & $80 /$ iv & $60-240$ & $129 \pm 75$ & $12.0 \pm 3.5$ & $7.2 \pm 2.16$ \\
\hline \multicolumn{6}{|l|}{ Current Study } \\
\hline Child's A & $40 /$ oral & $90 / 1.02 \pm 0.47$ & $45.45 \pm 0.133$ & $5.00 \pm 0.32$ & $6.60 \pm 2.90$ \\
\hline Child's B & $40 /$ oral & $120 / 1.44 \pm 0.43$ & $53.76 \pm 0.047$ & $7.73 \pm 1.1$ & $8.84 \pm 0.45$ \\
\hline Child's C & $40 /$ oral & $180 / 1.55 \pm 0.59$ & $64.4 \pm 0.17$ & $9.69 \pm 1.32$ & $3.48 \pm 1.40$ \\
\hline
\end{tabular}

Currently observed increase in systemic clearance among A and B groups of cirrhosis vis a vis healthy volunteers indicates compensated stage. Compensated stage is expressed by a compensatory increase in renal excretion of unchanged drug, due to insufficient detoxification capabilities of the $\operatorname{liver}^{24}$. The relatively decreased systemic clearance of the drug in group $\mathrm{C}$ cirrhosis may also be the result of higher age of patients in that category and hence their associated dwindling renal functions
(Nielsen 1973). It is also reported $^{25}$ that cirrhotics have essentially no non renal frusemide elimination.

\section{CONCLUSION:}

Current kinetic parameters among healthy Indian volunteers do not correspond to the earlier reports carried out mainly in Western countries. Such differences may be explained on various basis such as the difference in techniques, aging, sample selection, etc as explained above, but a 
certain genetic interplay influencing drug disposition should not be ruled out. Genetic differences is becoming commonly known and there are various approaches to create a 'tailor made' to reduce economic drug and curtail side effects.

Among Indian cirrhotic patients, the data obtained could not be effectively compared to earlier studies due to lack of conclusive data on the three types of cirrhosis. Thus our study was a pioneer study among the Indian subjects and also in the various categories of cirrhosis. Moreover, kinetic trend among $\mathrm{A}, \mathrm{B}$ and $\mathrm{C}$ type cirrhosis could not be compared to earlier reported trends, which could possibly be influenced by genetic factors.

\section{REFERENCES:}

1. Williams EJ, Iredale JP. Liver cirrhosis. Postgraduate Medical Journal 1998 Apr;74(870):193-202.

2. Cirrhosis: Hispanic Risk. About.com: Alcoholism \& Substance Abuse. http://alcoholism.about.com/library/blnaane ws010920.htm

3. Gines P, Fernandez-Esparrach G, Arroyo V. Ascites and renal functional abnormalities in cirrhosis. Pathogenesis and treatment. Baillieres Clin Gastroenterol 1997 Jun;11(2):365-85.

4. Puschet JB, Winaver J. Effects of diuretics on renal function. Handbook of physiology. Oxfo0rd Universoty Press. 1992:2335-407.

5. Kim EJ, Han KS, Lee MG. Gastrointestinal first-pass effect of furosemide in rats. $J$ Pharm Pharmacol 2000 Nov;52(11):133743.

6. Westphal JF, Brogard JM. Drug administration in chronic liver disease. Drug Saf. 1997 Jul;17(1):47-73.

7. Wolf CR, Smith G. Pharmacogenetics. British Medical Bulletin 1999;55(2):366-86.

8. Colombo S, Buclin T, Cavassini M, et al. Population pharmacokinetics of atazanavir in patients with human immunodeficiency virus infection. Antimicrob Agents Chemother 2006 Nov;50(11):3801-8.

9. Ruhnke M, Yeates RA, Pfaff G, et al. Single-dose pharmacokinetics of fluconazole in patients with liver cirrhosis. $J$ Antimicrob Chemother 1995 May;35(5):641-7.

10. Kumar R, Chawla YK, Garg SK, et al. Pharmacokinetics of omeprazole in patients with liver cirrhosis and extrahepatic portal venous obstruction. Methods Find Exp Clin Pharmacol 2003 Oct;25(8):625-30.

11. Kelly MR, Cutler RE, Forrey AW, et al. Pharmacokinetics of orally administered furosemide. Clin Pharmacol Ther 1974 Feb;15(2):178-86.

12. McCrindle JL, Li Kam Wa TC, Barron W, et al. Effect of food on the absorption of frusemide and bumetanide in man. Br J Clin Pharmacol 1996 Dec;42(6):743-6.

13. Wolf-Coporda A, Lovric Z, Huic M, et al. Determination of bioequivalence of two furosemide preparations; the effect of high doses of furosemide on some pharmacokinetic parameters.. Int J Clin Pharmacol Res 1996;16(4-5):83-8.

14. Rupp W. Pharmacokinetics and pharmacodynamics of Lasix. Scott Med J. 1974;19 Suppl 1:5-13.

15. Cutler RE, Blair AD. Clinical pharmacokinetics of frusemide. Clin Pharmacokinet 1979 Jul-Aug;4(4):279-96.

16. Johansson LC, Frison L, Logren U, et al. Influence of age on the pharmacokinetics and pharmacodynamics of ximelagatran, an oral direct thrombin inhibitor. Clin Pharmacokinet 2003;42(4):381-92.

17. Shinkuma D, Hamaguchi T, Kobayashi M, et al. Effects of food intake on the bioavailability of sulpiride from AEA filmcoated tablet having a $\mathrm{pH}$-dependent dissolution characteristic in normal or druginduced achlorhydric subjects. Int J Clin Pharmacol Ther Toxicol 1991 Aug;29(8):303-9.

18. Bradford CR, Prentice AG, Warnock DW, et al. Comparison of the multiple dose pharmacokinetics of two formulations of itraconazole during remission induction for acute myeloblastic leukaemia. J Antimicrob Chemother 1991 Oct;28(4):555-60.

19. Ramachandran A, Balasubramanian KA. Intestinal dysfunction in liver cirrhosis: Its role in spontaneous bacterial peritonitis. $J$ Gastroenterol Hepatol 2001 Jun;16(6):60712.

20. Gumurdulu Y, Yapar Z, Canataroglu A, et al. Gastric emptying time and the effect of cisapride in cirrhotic patients with autonomic neuropathy.J Clin Gastroenterol 2003 Feb;36(2):175-8.

21. Ishizu H, Shiomi S, Kawamura E, et al. Gastric emptying in patients with chronic liver diseases. Ann Nucl Med 2002 May;16(3):177-82. 
22. Gonzalez G, Arancibia A, Rivas MI, et al. Pharmacokinetics of furosemide in patients with hepatic cirrhosis. Eur J Clin Pharmacol 1982;22(4):315-20.

23. Verbeeck RK, Patwardhan RV, Villeneuve JP, et al. Furosemide disposition in cirrhosis. Clin Pharmacol Ther 1982 Jan;31(6):71925.

24. Traeger A, Hantze R, Penzlin M, et al. Pharmacokinetics and pharmacodynamic effects of furosemide in patients with liver cirrhosis. Int J Clin Pharmacol Ther Toxicol 1985 Mar;23(3):129-33.

25. Allgulander C, Beermann B, Sjogren A. Frusemide pharmacokinetics in patients with liver disease. Clin Pharmacokinet 1980 Nov-Dec;5(6):570-5.
26. Thomson PD, Melmon KL, Richardson JA, et al. Lidocaine pharmacokinetics in advanced heart failure, liver disease, and renal failure in humans. Ann. Intern. Med 1973 Apr;78(4):499-508.

27. Klotz U, Avant GR, Hoyumpa A, et al. The effects of age and liver disease on the disposition and elimination of diazepam in adult man. $J$ Clin Invest 1975 Feb;55(2):347-59.

28. Lewis GP, Jusko WJ. Pharmacokinetics of ampicillin in cirrhosis. Clin Pharmacol Ther 1975 Oct; 18(4):475-84.

29. Sawhney VK, Gregory PB, Swezey SE, et al. Furosemide disposition in cirrhotic patients. Gastroenterology 1981 Dec;81(6):1012-6. 